\title{
Membangun Kontrol Diri Remaja Melalui Pendekatan Islam dan Neuroscience
}

\author{
Ragwan Mohsen Alaydrus
}

Email: gwan.aydrus@gmail.com

\begin{abstract}
Adolescents are often associated with high work in risk taking behavior. Neuroscience experts then proposed hypotheses that tend to be related to adolescent brain development, in the prefrontal cortex and limbic systems. Through fMRI-related scanning is the cognitive ability that plays a role in self-regulation and decisionmaking is still growing until late adolescence. That's how the limbic system is so sensitive to socio-emotional stimuli. Therefore adolescents need to be changed. For these things can reduce the tendency of adolescents to behave deviant. Along with that, Hujjatul Islam Al-Ghazali also mentions self control as a testament to the strength of one's character. Preventive measures have been taken to improve adolescent selfcontrol and prevention in risky behaviors through various trainings. Nevertheless, the outcomes of the existing training proved not to provide long-term pricing. Furthermore this article discusses the approach that can be done by parents and educators as a combination of Islamic perspectives and neuroscience findings in assisting adolescents develop self-control.
\end{abstract}

Keywords: adolescent, Islamic parenting, neuroscience, self control, risk taking behavior

INTISARI

Remaja sering diasosiasikan dengan keterlibatan yang tinggi dalam perilaku berisiko (risk-taking behavior). Pakar neuroscience kemudian mengajukan hipotesis bahwa kecenderungan keterlibatan tersebut dipengaruhi oleh perkembangan otak remaja, terutama pada area korteks prefrontal dan sistem limbik. Melalui scan fMRI dilaporkan bahwa kemampuan kognitif yang berperan pada regulasi diri dan pengambilan keputusan masih terus berkembang hingga masa remaja akhir. Sementara tingginya aktivitas pada sistem limbik membuat remaja menjadi sangat sensitif pada stimulus sosio-emosional. Karenanya remaja perlu mengembangkan kontrol diri untuk menjaga fungsi eksekutif otak lebih dominan yang hal tersebut dapat mengurangi tendensi remaja untuk berperilaku menyimpang. Sejalan dengan itu, Hujjatul Islam Al -Ghazali juga menyebutkan bahwa kontrol diri adalah bukti kuatnya karakter seseorang. Usaha preventif telah dilakukan untuk meningkatkan kontrol diri remaja dan mencegah keterlibatan mereka dalam perilaku berisiko melalui berbagai pelatihan. Meski begitu, hasil dari pelatihan-pelatihan yang ada terbukti tidak memberi efektivitas jangka panjang. Selanjutnya artikel ini membahas mengenai pendekatan yang dapat dilakukan oleh orang tua dan pendidik sebagai kombinasi perspektif Islam dan temuan neuroscience dalam mendampingi remaja mengembangkan kontrol diri.

Kata kunci: kontrol diri, neuroscience, pengasuhan Islami, perilaku berisiko, remaja

$\mathrm{D}$ alam istilah psikologi perkembangan, remaja adalah tahapan kehidupan yang berada di antara masa kanakkanak dan dewasa. Konsepsi remaja sendiri memiliki dimensi kultural. Dalam pandangan barat, masa remaja adalah tahapan yang diawali dengan pubertas dan akan berakhir dengan dimulainya tanggung jawab sebagai orang dewasa (Santrock, 2010). Tahapan remaja dalam pandangan 
Psikologi dibedakan menurut rentang usianya sebagai masa remaja awal, remaja tengah, dan remaja akhir (Rathus, 2013).

Sementara itu, di dalam Al-Qur'an Allah menyebut kata balig untuk mengindikasikan waktu di mana anak telah mampu menerima beban syariat. Kata balig dalam Al- Qur'an sering diterjemahkan ke dalam bahasa Inggris sebagai puberty. Padahal konsepsi puberty di dalam perspektif Islam dan Psikologi barat cukup berbeda. Pubertas dalam perspektif psikologi mengacu pada kematangan seksual individu yang ditandai dengan perubahan fisik dan berkembangnya ciri seks primer dan sekunder (Santrock, 2010). Sedangkan maksud kata balig dalam AlQur'an diartikan sebagai puberty yakni masa dimana anak telah mencapai kesempurnaan akal. Hal ini digambarkan Allah dalam surat An-Nisa:

"Dan berikanlah kepada anak-anak yatim (yang sudah balig) harta mereka, jangan kamu menukar yang baik dengan yang buruk dan jangan kamu makan harta mereka bersama hartamu. Sesungguhnya tindakantindakan (menukar dan memakan) itu, adalah dosa yang besar." (QS. An-Nisa: 2)

"Dan janganlah kamu serahkan kepada orang-orang yang belum sempurna akalnya, harta (mereka yang ada dalam kekuasaanmu) yang dijadikan Allah sebagai pokok kehidupan. Berilah mereka belanja dan pakaian (dari hasil harta itu) dan ucapkanlah kepada mereka kata-kata yang baik." (QS. AnNisa: 5)

Tahapan balig ini pun berbeda-beda pada masing-masing anak, ada yang mencapai usia normal seperti 11 tahun, ada juga yang lebih lambat (Badriah, 2005). Tibanya balig ditandai saat seorang anak mengalami mimpi basah (maupun menstruasi bagi wanita):

"Diangkat pena catatan amal dari tiga orang: orang gila yang hilang akalnya sampai sadar kembali, orang tidur sampai ia bangun, dan anak kecil sampai ia bermimpi (balig)." (HR Abu Daud)

Psikologi menjelaskan bagaimana perubahan fisik, emosional, dan kognitif yang sangat signifikan di usia remaja sehingga sering digambarkan secara dramatis sebagai masa storm and stress (Lerner, 2008). Pandangan ini oleh sejumlah ahli dianggap terlalu berlebihan. Terkait hal ini Lerner (2008) dalam bukunya The Good Teen: Rescuing Adolescence from the Myths of the Storm and Stress Years mencoba mengajak kita untuk fokus pada kekuatan yang bisa ditumbuhkan oleh remaja daripada terus mengaitkan mereka dengan masalah perilaku. Bahkan Steinberg (2007) mengoreksi para penulis buku termasuk dirinya sendiri yang dahulu telah keliru memaknai storm and stress pada remaja. Ia mengatakan "we are now fairly certain that frequent, high intensity, angry fighting is not normative during adolescence" (Smetana, 2010).

Smetana (2010) kemudian meredefenisi istilah badai dan stress dengan lebih jelas merujuk kepada situasi yang seringkali dihadapi oleh remaja seperti meningkatnya konflik dengan orang tua, mood yang selalu berubah, dan seringnya remaja terlibat dalam perilaku berisiko. Lebih lanjut, Arnett (1995) menyebutkan bahwa perilaku remaja dikarenakan faktor media selain faktor teman, baik positif maupun negatif. Terkait dengan remaja rentan dengan perilaku berisiko, kondisi ini seakan didukung dengan adanya beberapa kasus pidana di Indonesia yang melibatkan remaja sebagai pelaku kejahatan. Beberapa diantaranya adalah kasus pembunuhan dan pemerkosaan terhadap Yuyun (14 tahun) yang dilakukan oleh 14 orang yang hampir seluruhnya berusia remaja (16-20 tahun) yang ditulis oleh reporter Putro (2016). Kemudian lima remaja dilaporkan tewas disebabkan menenggak minuman keras oplosan (Kompas, 2017). Lalu yang terbaru adalah dua remaja yang tertangkap setelah menjadi pengurus grup pedofilia Official Candy'S Group di facebook (Manalu, 2017).

Beberapa penelitian telah mencoba mengungkap faktor pendorong remaja terlibat dalam perilaku berisiko. Lestary dan Sugiharti (2011) menemukan bahwa 
teman sebaya memiliki pengaruh kuat dalam keputusan remaja terlibat dalam perilaku berisiko selain karena kurangnya pengetahuan dan bimbingan dari orang tua. Sementara Rolison dan Scherman (2002) mengungkapkan bahwa remaja terdorong untuk mencoba hal-hal berbahaya karena ingin mencari sensasi untuk kepuasan diri.

Perilaku berisiko yang ditampilkan oleh remaja adalah dampak dari rendahnya kontrol diri yang dimiliki oleh remaja. Disebutkan pada risetnya Wills dan Dishion (2004) bahwa kontrol diri mengaitkan kognitif pada remaja untuk pencegahan dari perilaku berisiko. Kontrol diri remaja dapat menjadi faktor protektif agar tidak menjadikan remaja berperilaku negatif saat mengalami depresi (Yang, dkk., 2018). Kontrol diri remaja menjadi faktor mediasi perilaku bermasalah remaja dengan pengasuhan orangtua (Finkenauer, dkk., 2005).

Kontrol diri erat kaitannya dengan fungsi kognitif yaitu fungsi eksektifnya. Hal ini dapat dilihat dari studi Blair dan Razza (2007) bahwa kontrol diri anak dapat berpegaruh pada fungsi akademis anak dengan mengaktifkan fungsi eksekutif pada otak. Lebih lanjut, fungsi eksekutif pada individu akan meningkatkan kontrol diri pada individu yang telah mengalami kelelahan ego yang akan menjadi sumber untuk melakukan perilaku yang maladaptif (Baumeister, 2002). Adanya riwayat lesi neuropsikologi pada individu akan mempengaruhi kontrol diri seseorang (Beaver, Wright, \& Delisa, 2007). Kontrol diri penting dimiliki oleh remaja sebagai bentuk upaya untuk pencegahan dari perilaku berisiko. Tulisan ini bertujuan untuk membahas kontrol diri melalui perspektif neuroscience dan bagaimana pandangan Islam mengenai usaha preventif yang tepat.

\section{Perilaku Berisiko berhubungan dengan Atifitas Otak}

Perilaku berisiko (risk-taking behaviors) adalah perilaku sebagai hasil interaksi dari kondisi biopsikososial remaja dengan lingkungannya (Lipsitt \& Mitnick, 1991). Perilaku berisiko ini termasuk perilaku seksual, penyalahgunaan zat, dan pelanggaran dalam norma-norma sosial di masyarakat. Lipsitt dan Mitnick (1991) kemudian menjabarkan bahwa kematangan biologis mempengaruhi aspek kognitif, persepsi diri, persepsi terhadap lingkungan sekitar, dan nilai-nilai yang dianut secara personal. Hal-hal ini kemudian yang mempengaruhi remaja untuk terlibat dalam perilaku berisiko dengan didukung oleh peran teman sebaya dan bagaimana mereka memandang akibat dari perbuatannya. Berdasarkan kerangka tersebut, kemudian para ahli mencoba menemukan faktor yang membuat remaja berpikir secara egosentris dan terlibat pada perilaku berisiko melalui pendekatan neuroscience.

\section{Perkembangan Korteks Pre-Frontal sebagai Fungsi Eksekutif Otak}

Korteks prefrontal adalah bagian dari otak yang memiliki fungsi eksekutif dalam proses high-order thinking, kecerdasan moral, penilaian, pengambilan keputusan, serta kontrol diri (Steinberg, Bornstein, \& Vandell, 2010; Anderson, 2015). Korteks prefrontal ini memiliki tiga area dengan fungsi eksekutif yang masih berkembang yaitu lateral frontal cortex, orbitofrontal cortex, dan ventromedial prefrontal cortex. Lateral frontal cortex berfungsi dalam perencanaan dan mengontrol rangsangan, orbitofrontal cortex mengambil peran dalam menimbang risiko dan keuntungan untuk perilaku yang bertujuan, sedangkan ventromedial prefrontal cortex berfungsi penting dalam pengambilan keputusan intuitif (Steinberg, dkk., 2010; Crone, 2016). Ketiga fungsi eksekutif ini berperan saat remaja berperilaku atau mengambil keputusan yang berorientasi jangka panjang. Misalnya, memilih apakah harus mengerjakan tugas sekolah atau keluar rumah bersama teman, dan mempertimbangkan apakah akan melakukan perbuatan berisiko ataukah tidak.

Melalui penelitian mengenai anatomi otak, ditemukan bahwa prefrontal cortex mengalami kematangan paling akhir dibanding bagian otak lainnya. Sementara sistem respon dan sensori matang paling awal disusul dengan perkembangan signifikan pada area temporal dan pariental yang berperan pada kemampuan bahasa dan spasial (Casey, dkk., 2008). Lebih lanjut, pada 
hasil studi lainnya juga mencoba membandingkan perbedaan otak remaja dan orang dewasa menggunakan functional Magnetic Resonance Imaging (fMRI), ditemukan bahwa bagian temporal dan parietal yang tampak serupa kecuali pada area prefrontal-kortex di mana otak orang dewasa menunjukkan myelinasi yang lebih dari otak remaja. Perbedaan lainnya tampak saat dilakukan eksperimen dengan menampilkan gambar beberapa wajah dan meminta peserta untuk mengidentifikasi emosi dari setiap gambar yang ada. Kemudian, peneliti melakukan scanning untuk memantau aktivitas pada otak remaja dan dewasa. Otak remaja ternyata memperlihatkan aktivitas yang lebih pada bagian amygdala sebagai pusat reaksi instan, sementara otak remaja akhir dan dewasa ditemukan lebih aktif pada bagian korteks prefrontal sehingga memungkinkan persepsi yang dihasilkan lebih berdasar penalaran (Davis \& D'Amato, 2010). Kelemahan fungsi eksekutif ini kemudian membantu para peneliti untuk menjelaskan mengapa remaja sering terlibat pada perilaku berisiko (Weiten, 2012).

Lebih lanjut, ada interaksi dua jaringan otak yang menjelaskan keterlibatan remaja pada perilaku berisiko dan kegemaran untuk mencari hal-hal baru (Steinberg, 2007). Pertama, jaringan sosioemosional yang berpusat pada sistem limbik, jaringan ini berperan pada reward system dan sangat responsif pada stimulus sosialemosional. Beberapa penelitian menemukan meningkatnya aktivitas di area subkortikal limbik yaitu amygdala juga tingginya level responsi saat remaja membuat keputusan berisiko dan memproses stimulus emosional. Kedua, jaringan kontrol-kognitif yang mengakomodasi fungsi perencanaan, berpikir jangka panjang serta regulasi diri. Jaringan ini berpusat pada korteks prefrontal dan berperan penting untuk mengontrol perilaku serta pilihan-pilihan seseorang agar sejalan dengan tujuan. Casey, Jones, dan Hare (2008) mengembangkan model neurobiological yang menerangkan bias perilaku remaja sebagai sebab tingginya aktivitas pada sistem limbik yang belum sejalan dengan kematangan pada fungsi eksekutif otak. Hal ini berbeda dengan otak anak yang menunjukkan fungsi sosio-emosional dan kontrol-kognitif yang masih berkembang bersamaan, dan otak orang dewasa yang memperlihatkan kematangan yang seimbang dari kedua fungsi tersebut.

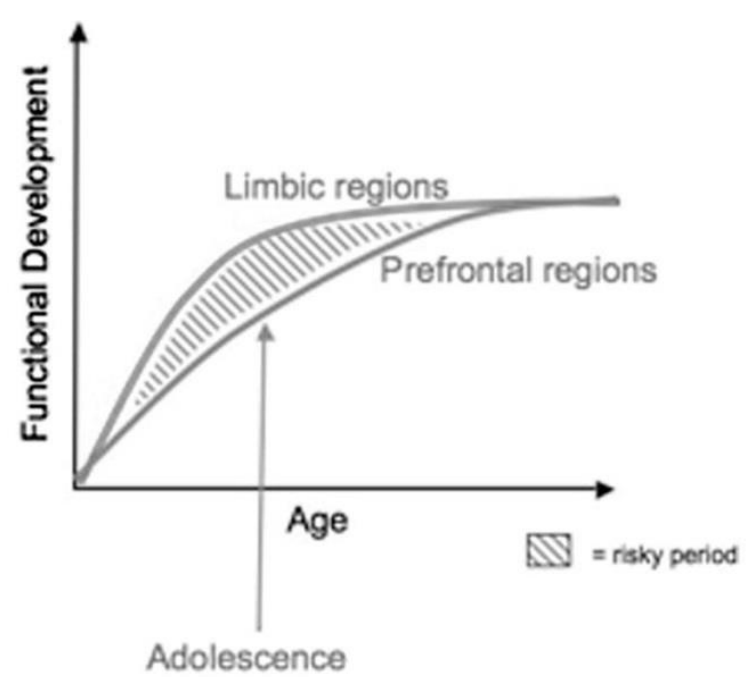

Gambar 1 Model Neurobiological oleh Casey, et al (2008)

Model neurobiological oleh Casey, et al (2008) menjelaskan interaksi antara area limbik dan korteks prefrontal dalam perilaku berisiko dan reaksi emosional individu. Model ini menjelaskan bahwa dalam situasi emosional yang menonjol, peran sistem limbik akan lebih kuat dibandingkan fungsi korteks prefrontal. Respon terhadap reward akan lebih mempengaruhi remaja dalam bersikap karena belum matangnya fungsi kontrol perilaku (Steinberg, 2007; Colver \& 
Longwell, 2013). Akan tetapi, Casey dan Claude (2013) kemudian mengklarifikasi anggapan bahwa remaja sama sekali belum memiliki kapasitas dalam mengambil keputusan yang optimal. Remaja akan mampu bersikap rasional dan membuat keputusan dengan baik jika dihadapkan pada situasi yang lebih tenang jauh dari tekanan emosional. Meski begitu, penjelasan neuroscience ini telah membantu kita untuk memahami tantangan remaja dalam regulasi dan kontrol diri. Di bagian selanjutnya, akan dibahas mengenai kontrol diri dalam perspektif Islam dan psikologi modern serta usaha membangun kontrol diri remaja.

\section{Kontrol diri dalam Perspektif Islam dan Psikologi Modern}

Kontrol diri bagi remaja didefinisikan sebagai kemampuan untuk secara aktif dan sengaja dalam mengatur, membatasi, menunda, atau mencegah dorongan emosional, pikiran atau perilaku dengan tujuan mencapai imbalan lebih besar di kemudian hari, daripada kompensasi yang segera namun kecil (Brier, 2014).

Dalam Islam, kontrol diri adalah bagian dari kesabaran, bahkan tergolong pada tingkatan yang paling tinggi di antara bentuk kesabaran lainnya. Menurut Ibnul Qoyyim Al-Jauziyah derajat kesabaran yang paling berat adalah menjauhi larangan yang umumnya merupakan sesuatu yang digemari, dalam hal ini seseorang bersabar meninggalkan kesenangan sementara di dunia demi kesenangan di masa mendatang di negeri akhirat (Al-Jauziyah, 2006). Konsep ini kita kenal sebagai delay gratification.

Terkait hal ini Allah SWT berfirman dalam Al-Qur'an:

"Hai kaumku, sesungguhnya kehidupan dunia ini hanyalah kesenangan (sementara), dan sesungguhnya akhirat itulah negeri yang kekal" (QS. Al- Mukmin: 39)

Dalam ayat ini, Allah menekankan pada manusia bahwa kesenangan dunia apapun bentuknya bersifat sementara, dan bagi orang-orang yang mengerjakan kebaikan dan menahan diri dari mengerjakan kejahatan akan diberi balasan yang bersifat abadi dan lebih besar dari kemewahan di dunia kelak di akhirat nanti. Realisasi dari pemenuhan kebutuhan itu pun harus dengan mengontrol diri agar tidak berlebihan.

"Hai anak Adam, pakailah pakaianmu
yang indah di setiap (memasuki)
19espon, makan dan minumlah, dan
janganlah berlebih-lebihan.
Sesungguhnya Allah tidak menyukai
orang-orang yang berlebih-lebihan."
(QS. Al-A'raf: 31)

Di sisi lain, Allah SWT juga memerintahkan untuk mengontrol diri dan bersikap moderat dalam menjalankan tuntunan agama.

\section{"Dan janganlah engkau jadikan tanganmu terbelenggu pada lehermu dan jangan (pula) engkau terlalu mengulurkannya (sangat pemurah) nanti kamu menjadi tercela dan menyesal" (QS. Al-Isra: 29)}

Terdapat dua hal penting yang berperan dalam menentukan perilaku manusia, yaitu akal (aql) dan hati (qalb). Menurut Al-Ghazali (2008), 'aql hakikatnya adalah insting yang diciptakan untuk menalar khususnya fenomena alam dan ayat-ayat kauniyah Allah. Sementara hati ibarat pemimpin bagi seluruh organ tubuh manusia. Hati menjadi penentu kepribadian individu, mengontrol perilaku serta dorongan baik maupun buruk. Pengetahuan yang diperoleh dari aql mendorong qalb untuk tunduk dan melaksanakan tuntunan Allah. Jika 'qalb gagal melakukannya, maka individu tersebut akan condong kepada kepada kejahatan dan derajatnya tak lebih tinggi dari binatang (Zarkasyi \& Cholik, 2016).

Di sinilah kemudian dipahami bahwa dalam Islam kemampuan kontrol diri erat kaitannya dengan berfungsinya qalb yang condong kepada ketaatan. Olehnya itu dalam Islam untuk menjaga diri dari berbuat kerusakan, individu diarahkan untuk menjalankan ibadah yang akan menjadi perisai dari perbuatan dosa.

Allah SWT berfirman: 
"Bacalah apa yang telah diwahyukan kepadamu, yaitu Al Kitab (Al Quran) dan dirikanlah salat. Sesungguhnya salat itu mencegah dari (perbuatanperbuatan) keji dan mungkar. Dan sesungguhnya mengingat Allah (salat) adalah lebih besar (keutamaannya dari ibadat-ibadat yang lain). Dan Allah mengetahui apa yang kamu kerjakan." (QS. Al-Ankabut: 45)

\section{Rasulullah $S A W$ bersabda:}

“...Wahai sekalian pemuda, siapa di antara kalian telah mempunyai kemampuan, maka hendaklah ia menikah, karena menikah itu dapat menundukkan pandangan, dan juga lebih bisa menjaga kemaluan. Namun siapa yang belum mampu, hendaklah ia berpuasa, sebab hal itu dapat meredakan nafsunya" (HR. Bukhari, No 4678)

Menurut Imam Al-Ghazali, kontrol diri yang baik akan mengantarkan seseorang pada kekuatan karakter. Sementara kontrol diri membutuhkan kematangan spiritual ditambah dengan disiplin diri berupa tazkiyatun-nafs dan riyadhah yang membuat seseorang yakin atas balasan dari Allah (delay gratification). Karena itu seseorang yang matang secara spiritual akan mampu menahan diri dari kesenangan terlarang yang bersifat sementara (Abdullah, 2014).

Beberapa penelitian mengenai kontrol diri dan hubungannya pada kesuksesan individu telah dipublikasikan. Studi yang ada dimulai dari sebuah eksperimen dilakukan oleh Stanford University pada tahun 1989 (Mischel, Shoda, \& Rodriguez, 1989) dengan melibatkan anak-anak prasekolah. Sebagai intervensi, peneliti meninggalkan anak di sebuah ruangan. Peneliti memberikan satu respons kepada anak dan menekankan bahwa anak boleh memakan respons tersebut dan anak boleh memanggil peneliti dengan membunyikan bel jika ia tidak mau menunggu lebih lama. Namun, jika anak berhasil menunggu tanpa memakan satu respons itu, anak akan mendapatkan dua respons. Penelitian follow up dilakukan 10 tahun kemudian kepada anak yang terlibat pada eksperimen delay gratification ini. Hasilnya, orang tua dari anak yang menunggu lebih lama mengungkap bahwa anak mereka kompeten secara akademik dan sosial jika dibandingkan dengan teman sebayanya. Mereka juga lebih mampu untuk mengatasi frustasi dan mengendalikan diri.

Studi longitudinal dilanjutkan oleh Casey, dkk. (2011) kepada subjek penelitian pada usia 40 tahunan. Temuan menunjukkan bahwa anak dengan performa rendah pada penelitian delay gratification puluhan tahun yang lalu ternyata memperlihatkan rendahnya kontrol diri pada tugas eksperimen dewasa yang diberikan. Hal sebaliknya terjadi pada subjek dengan performa yang baik ternyata memperlihatkan kontrol diri yang tinggi dengan korteks prefrontal yang lebih aktif di masa dewasanya. Temuan penelitian di atas mengindikasikan kontrol diri yang dibangun sejak dini dapat terus berkembang dan mempengaruhi coping skill hingga individu mencapai usia dewasa.

Di sisi lain, intervensi terhadap perilaku berisiko remaja justru lebih umum dilakukan melalui pemberian edukasi (knowledge transfer) dengan harapan wawasan yang dimiliki remaja dapat membantunya untuk mengendalikan diri. Terkait hal ini Laurence Steinberg, pakar psikologi remaja dari Temple University mengkritisi upaya tersebut, ia lalu mengemukakan intervensi yang dapat dilakukan orang tua maupun pendidik kepada anak remajanya (Steinberg, 2007):

"More than 90\% of all American highschool students have had sex, drug, and driver education in their schools, yet large proportions of them still have unsafe sex, binge drink, smoke cigarettes, and drive recklessly (often more than one of these at the same time). Strategies such as raising the price of cigarettes, more vigilantly enforcing laws governing the sale of alcohol, expanding adolescents' access to mental-health and contraceptive services, and raising the driving age would likely be more effective in limiting adolescent smoking, substance abuse, pregnancy, and automobile fatalities than 
strategies aimed at making adolescents wiser, less impulsive, or less shortsighted. Some things just take time to develop, and, like it or not, mature judgement is probably one of them."

Menurut Steinberg, sebagai implikasi dari temuan mengenai korteks prefrontal, tindakan pencegahan perilaku menyimpang pada remaja sebaiknya dilakukan dengan mengubah konteks (lingkungan atau regulasi). Steinberg menilai bahwa program edukasi di luar atau di dalam sekolah dirasa kurang efektif dalam mengurangi jumlah remaja yang terlibat dalam narkoba, seks bebas, dan penyimpangan lainnya. Program yang ada belum cukup karena hanya bertujuan mengubah anak dengan memberikan pengetahuan. Steinberg meragukan bentuk preventif tersebut di samping belum ada penelitian yang dapat membuktikan kemungkinan untuk mempercepat kematangan regulasi diri pada remaja. Steinberg (2007) mengajukan hipotesis bahwa meskipun kemampuan penalaran remaja telah mencapai level yang setara dengan orang dewasa di usia 16 tahun, namun kapasitas psikososialnya masih belum matang dalam hal kontrol diri, orientasi terhadap masa depan, dan pertahanan terhadap pengaruh teman sebaya. Dari sini kita dapat menyimpulkan bahwa di usia remaja sangat penting adanya bimbingan serta lingkungan yang baik untuk menumbuhkan pengendalian diri.

\section{Membangun Kontrol Diri Remaja}

Dari uraian mengenai perkembangan kognitif anak baik ditinjau dari perspektif psikologi, neuroscience, dan Al-Qur'an, maka dapat dirumuskan langkah yang dapat ditempuh oleh orang tua untuk membantu remaja mengembangkan kontrol diri jika dibagi menjadi dua:

Dari pembahasan sebelumnya mengenai eksperimen delay gratification kita tahu bahwa potensi kontrol diri individu telah terlihat sejak usia prasekolah. Bahkan, kemampuan ini telah berkembang di tahun kedua saat anak mencoba untuk menjadi otonom. Di level ini kontrol diri dimulai dari tendensi anak untuk patuh kepada orang tua atau pengasuhnya. Jika orang tua bersikap responsif terhadap kebutuhan anak dan tidak memperlihatkan ekspektasi yang berlebihan, maka anak akan cenderung lebih patuh (Shaffer \& Kipp, 2002). Sementara jika orang tua menunjukkan kontrol yang sangat ketat pada anak, anak akan terbiasa untuk bergantung pada pengaruh eksternal dan kurang mampu untuk mengembangkan kontrol diri internal (Fox \& Calkins, 2003).

Sementara mendidik anak patuh kepada tuntunan syariat dapat dimulai saat anak mencapai usia mumayyiz yaitu 7 tahun, berdasarkan hadis Rasulullah $S A W$ (Al-Atiq, 2004):

"Perintahkanlah anak-anakmu salat pada usia 7 tahun. Pukullah mereka pada usia 10 tahun, dan pisahkan juga mereka dari tempat tidur mereka." (Sunan Abi Dawud No. 495).

Membiasakan anak untuk menjalankan tuntunan syariah hanya bisa dilakukan saat anak sudah mulai mengembangkan kemampuan berpikir, karena itu hadis ini secara tidak langsung memberikan informasi mengenai usia mumayyiz pada anak. Selain itu memerintahkan salat pada anak juga mengindikasikan kewajiban syariat lainnya seperti puasa, menutup aurat, dan menahan diri dari melakukan perbuatan tercela. Mengajarkan anak pada usia mumayyiz sudah bisa dilakukan melalui dialog dengan menerangkan mengenai sebab-akibat. Tahap pembentukan ini tercatat dalam beberapa ayat surat Luqman:

"Dan (ingatlah) ketika Luqman berkata kepada anaknya, di waktu ia memberi pelajaran kepadanya: "Hai anakku, janganlah kamu mempersekutukan Allah, sesungguhnya mempersekutukan (Allah) adalah benar-benar kezaliman yang besar" (QS. Luqman: 13)

"(Luqman berkata): "Hai anakku, sesungguhnya jika ada (sesuatu perbuatan) seberat biji SAW, dan berada dalam batu atau di langit atau di dalam bumi, niscaya Allah akan 
mendatangkannya (membalasnya). Sesungguhnya Allah Maha Halus lagi Maha Mengetahui." (QS. Luqman: 16)

"(Luqman berkata) Hai anakku, dirikanlah salat dan suruhlah (manusia) mengerjakan yang baik dan cegahlah (mereka) dari perbuatan yang mungkar dan bersabarlah terhadap apa yang menimpa kamu. Sesungguhnya yang demikian itu termasuk hal-hal yang diwajibkan (oleh Allah)" (QS. Luqman: 17).

"Dan janganlah kamu memalingkan mukamu dari manusia (karena sombong) dan janganlah kamu berjalan di muka bumi dengan angkuh. Sesungguhnya Allah tidak menyukai orang-orang yang sombong lagi membanggakan diri." (QS. Luqman: 18)

"Dan sederhanalah kamu dalam berjalan dan lunakkanlah suaramu. Sesungguhnya seburuk-buruk suara ialah suara keledai." (QS. Luqman: 19)

Menurut Shihab (2007), ayat-ayat di atas menghimpun empat dasar pokok pendidikan yaitu akidah, ibadah, akhlak terhadap orang lain, dan akhlak terhadap diri sendiri. Luqmanul Hakim digambarkan sedang mengajarkan anaknya akan prinsipprinsip yang harus diinternalisasi demi membangun akhlak sang anak. Di sini Luqmanul Hakim memfungsikan perannya sebagai ayah dalam menasihati anak dengan kelembutan, di samping ia juga menggunakan perumpaan untuk memberikan pemahaman yang jelas kepada anak (Abidin, 2008). Beberapa ayat di atas dapat kita tadabburi sebagai pelajaran dalam membangun pengendalian diri:

Pada ayat ke-13 Allah SWT menggambarkan bagaimana Luqman mengenalkan mengenai eksistensi Allah sebagai Tuhan Yang Maha Esa. Sementara di ayat ke-16 Luqman membangun keyakinan pada anak bahwa segala bentuk ia akan diganjar sesuai dengan apa yang ia perbuat. Dengan berpedoman pada ayat ini orang tua dapat membangun kemampuan self-monitoring dalam diri anak yang bersumber dari keyakinan bahwa ada Allah yang selalu mengawasi gerak-geriknya (muraqabah) sehingga anak pun akan berusaha menghindari perbuatan tercela (Abidin, 2008).

Kemudian pada ayat ke-17 Luqman memberi petuah kepada sang anak yang mengandung tiga kewajiban yaitu: mendirikan salat sebagai representasi kewajiban beribadah kepada Allah SWT, beramal ma'ruf nahi mungkar sebagai bentuk kewajiban kepada manusia, dan bersabar, sebagai langkah solutif yang harus dilakukan bagi anak saat menghadapi hal apapun yang menimpanya. Pada ayat 18 Luqman mengajarkan sang anak tentang pengendalian diri pada pergaulan sosial yang terwujud nyata melalui perilaku, yaitu untuk tidak memalingkan muka dan tidak berjalan dengan angkuh. Disini Luqman menyebutkan contoh konkrit terlebih dahulu sebagai wujud ekspektasi bagi anak untuk menghindari kesombongan yang disebutkan kemudian. Pada ayat ke 19 Allah menggambarkan bagaimana Luqman mendidik anaknya tentang kesederhanaan dan sikap tidak berlebihan pada dua hal: berjalan dan bersuara. Orang bisa mengenali kepribadian seseorang tentu dari dua aspek, tindakan dan ucapannya. Dengan ayat ini Allah seakan mengajarkan bahwa seseorang perlu menjaga tindakan dan ucapannya agar selalu santun dan lembut dalam berinteraksi dalam masyarakat.

Beberapa ayat dalam Surat Luqman ini memberi tahu kita bahwa kontrol diri sesungguhnya bersumber dari perasaan selalu diawasi oleh Allah SWT yang kemudian berhasil melahirkan amal shalih dan kemampuan bersikap dengan akhlak yang mulia. Tahap pembentukan ini tidak berarti baru akan dimulai ketika anak mencapai usia mumayyiz, tapi seharusnya sudah dilakukan saat anak ada dalam tahap pre-mumayyiz (sebelum 7 tahun) melalui pembiasaan dan modeling kepada orang tuanya. Imam Al- Ghazali menekankan akan pentingnya mengajarkan pendidikan agama, akhlak serta aktivitas fisik kepada anak melalui bermain (Sulaiman, Jamsari, \& Noh, 2015). Orang tua dapat membiasakan beberapa aktivitas yang dapat melatih fungsi eksekutif otak. Misalnya mencuci tangan, tidur sesuai jam rutin, mengucapkan 
alhamdulillah sebagai bentuk regulasi diri anak.

Sesungguhnya mendampingi anak tidak terbatas pada usia tertentu, namun usaha pendampingan di sini dimaksudkan sebagai pendekatan orang tua dan pendidik kepada anak usia remaja dalam mengembangkan kontrol diri. Dorongan fisiologis yang tidak diimbangi kematangan bagian korteks prefrontal pada remaja memungkinkan mereka untuk terlibat pada perilaku berisiko. Bahkan kisah terkait hal ini terjadi pada masa Rasulullah $S A W$ (Qardhawi, 1998) sebagaimana diceritakan pada hadis di bawah ini:

Dari Abi Umamah ra berkata bahwa pada suatu hari datang seorang pemuda yang meminta izin kepada Rasulullah SAW untuk berzina. Orang sekelilingnya berpaling kepadanya kemudian marah dan melarangnya melakukan itu. Namun Rasulullah SAW dengan lembut menasihati pria tersebut. Berkata (Rasulullah SAW): "Bawakan dia dekat denganku". Maka pemuda itu telah mendekati Baginda SAW. (Abu Umamah) berkata: maka (pemuda itu) telah duduk (dekat dengan Rasulullah SAW). Rasulullah SAW bersabda: "Adakah kamu suka itu (perbuatan zina) terjadi kepada Ibumu?" Lantas pemuda itu menjawab: "Demi Allah, tidak! Allah jadikan aku tebusan bagimu!". Rasulullah SAW menyambung: "(Begitulah juga halnya) orang ramai tidak suka hal itu (terjadi) kepada ibu-ibu mereka".Rasulullah SAW bersabda lagi: "Adakah kamu suka itu (perbuatan zina) terjadi kepada anak perempuanmu?" Lantas pemuda itu menjawab: "Demi Allah, tidak! Allah jadikan aku tebusan (kematianku) bagimu!". Rasulullah SAW menyambung: "Begitulah juga halnya) orang ramai tidak suka hal itu (terjadi) kepada anak-anak perempuan mereka". Rasulullah SAW mula bersabda: "Adakah kamu suka itu (perbuatan zina) terjadi bibi-bibimu, saudari ayahmu?" Lantas pemuda itu menjawab: "Demi Allah, tidak! Allah jadikan aku tebusan (kematianku) bagimu!" Rasulullah SAW menyambung: "(Begitulah juga halnya) orang ramai tidak suka hal itu (terjadi) kepada bibi-bibimu". Rasulullah SAW bersabda lagi: "Adakah kamu suka itu (perbuatan zina) terjadi kepada bibi-bibimu, saudari ibumu?" Lantas pemuda itu menjawab: "Demi Allah, tidak! (Aku lebih sanggup) Allah jadikan aku tebusan (kematianku) bagimu!". Rasulullah SAW menyambung: "Begitulah juga halnya) orang ramai tidak suka hal itu (terjadi) kepada bibi-bibi mereka mereka". Abu Umamah berkata: Maka Rasulullah SAW meletakkan tangannya di atas pemuda itu, lalu berdoa: "Allahummaghfir zanbahu, wa tohhir

qalbahu, wa hassin farjahu" Artinya ("Ya Allah ampunkanlah dosanya, bersihkanlah/sucikanlah hatinya (dari memikirkan sesuatu maksiat), dan jagalah kemaluannya (dari melakukan zina)". Selepas itu, pemuda itu tidak lagi memandang sesuatu (yang berupa maksiat (terutama zina), natijah maqbulnya doa Nabi SAW). (HR Ahmad)

Dari hadis ini kita dapat mengambil beberapa poin pelajaran mengenai bagaimana langkah Rasulullah $S A W$ dalam menghadapi pemuda dalam kisah di atas:

1. Saat mengetahui anak remaja (pemuda) memperlihatkan kecenderungan untuk berperilaku secara menyimpang, Rasulullah $S A W$ tidak memperlihatkan sikap reaktif seperti menghakimi atau memarahi.

2. Rasulullah $S A W$ bersikap tenang dengan menunjukkan penerimaan (dengan memanggil pemuda tersebut).

3. Rasulullah melakukan pendekatan kepada pemuda tersebut dengan komunikasi secara face to face (berhadap-hadapan) untuk memudahkan sang pemuda menerima pesan yang akan disampaikan. Langkah ini juga menunjukkan bagaimana Rasulullah $S A W$ menempatkan sang pemuda layaknya sahabat; pendekatan ini penting 
dilakukan pada anak yang telah balig (Hamzah, 1991).

4. Rasulullah tidak langsung menasehati bahwa berzina itu haram, dan sebagainya, akan tetapi beliau $S A W$ terlebih dahulu berdialog dengan menanyakan beberapa pertanyaan yang merangsang penalaran dan selfreflective. Langkah ini bermanfaat untuk mengaktifkan korteks prefrontal yang pada akhirnya membantu remaja mengambil keputusan secara tepat. Dalam berbicara dengan pemuda tersebut Rasulullah $S A W$ juga menggunakan kalimat yang tidak begitu panjang dan berbelit-belit dalam menasehati, akan tetapi beliau memancing penalaran secara induktif dan membiarkan pemuda menyimpulkan keputusan yang tepat.

5. Rasulullah mendoakan pemuda tersebut dengan tiga hal: Agar Allah mengampuni dosa sang anak, mensucikan hati, dan menjaga kemaluan. Doa ini dapat memberikan kita beberapa pemahaman: yang pertama bagi orang tua untuk selalu mendoakan anak agar terjauh dari perbuatan menyimpang, kedua, untuk berhenti dari melakukan perilaku menyimpang, anak perlu menyadari bahwa perbuatan yang ia lakukan adalah tercela (dosa) dan dengannya ia perlu bertaubat kepada Allah, kemudian menyucikan hati agar mampu membentengi diri dari dorongan syahwat, lalu dengan usaha nyata menghindari perbuatan zina. Hal ini mengindikasikan bahwa usaha preventif dalam menghindari perilaku menyimpang perlu dibangun dengan menyentuh sisi spiritualitas remaja. Ketiga, Rasulullah mengucapkan doa di atas sampai terdengar oleh sahabat, artinya Rasulullah tidak mengucapkannya secara lirih. Hal ini juga berarti memungkinkan bagi pemuda tersebut untuk mendengar doa ini. Bagi pemuda atau anak remaja, doa tersebut adalah bentuk ekspektasi dari role model pemuda tersebut kepadanya. Mengapa role model? Karena pada umumnya manusia akan meminta saran ataupun persetujuan kepada seseorang yang ia hormati atau teladani. Dalam hal ini role model anak tersebut adalah Rasulullah karena ia mendatangi Rasulullah untuk memberikan pandangan mengenai hal yang serius (zina). Rasulullah mengucapkan doa itu di hadapan sang pemuda mengindikasikan pentingnya bagi orang tua sebagai role model bagi remaja untuk menaruh ekspektasi dan menyampaikan ekspektasi tersebut kepada mereka.

Brier (2014) menggaris bawahi bahwa ekspektasi memiliki efek luar biasa dan berdampak secara langsung pada level motivasi remaja. Remaja yang yakin bahwa mereka mampu akan lebih terdorong dan berhasil dalam memelihara kontrol diri. Sementara remaja yang memiliki kurang memiliki keyakinan akan lemah pula dalam motivasi dan usahanya untuk mengontrol diri. Sejalan dengan informasi ini McCullough dan Carter (2013) menyimpulkan bahwa agama mampu untuk memotivasi seseorang dalam regulasi dan kontrol diri. Hal ini seakan terbukti ketika sahabat yang meriwayatkan hadits di atas kemudian mengabarkan "Selepas itu, pemuda itu tidak lagi memandang sesuatu (yang berupa maksiat)".

\section{Simpulan}

\section{Simpulan dan Saran}

Riset terkini mengenai perkembangan otak remaja memudahkan kita memahami faktor yang mempengaruhi remaja terlibat dalam perilaku berisiko. Reward system yang semakin aktif saat anak memasuki masa pubertas membuat remaja cenderung mencari hal-hal baru dan menyenangkan. Di sisi lain, kematangan fungsi eksekutif otak anak masih berlangsung hingga anak mencapai usia dewasa, ini menyebabkan pengambilan keputusan dan pemecahan masalah menjadi sesuatu yang tidak mudah terlebih dengan adanya pengaruh lingkungan dan teman sebaya. Berangkat dari kondisi ini, pakar psikologi remaja mempercayai pentingnya rekayasa terhadap konteks yang dihadapi remaja, juga peran orang tua untuk mengembangkan kontrol 
diri sebagai penentu keterlibatan remaja pada perilaku berisiko. Dalam perspektif Islam, membangun kontrol diri remaja melibatkan pendekatan psikologis dan spiritual. Fondasi spiritual adalah aspek penting yang harus dibangun pertama kali dalam diri anak berawal dari menanamkan tauhid dan keyakinan atas pengawasan-Nya, lalu berlanjut kepada usaha remaja dalam penguasaan diri melalui mujahadah. Fondasi psikologis dibangun dengan mengembangkan sikap bersahabat dan penerimaan kepada remaja sebagaimana yang ditunjukkan oleh Rasulullah $S A W$ kepada seorang pemuda yang meminta izin untuk berzina. Penerimaan yang ditunjukkan oleh orang tua akan membuat remaja tidak terfokus mencari pengakuan atau terpengaruh teman sebayanya pada perilaku menyimpang. Di samping itu, membangun komunikasi dan dialog bersama remaja bertujuan mengembangkan kemampuan reasoning, problem solving, dan decision making pada remaja. Dengan terus membiasakan gaya komunikasi ini, orang tua telah membantu remaja untuk mendayagunakan fungsi korteks prefrontalnya.

\section{Saran}

Berdasar paparan di atas, remaja perlu mendapatkan peran lingkungan di sekitarnya baik rumah, sekolah, dan masyarakat untuk mengembangkan kontrol diri dengan berbagai pendekatan Islami. Hal ini dikarenakan temuan dalam bidang neuroscience membuktikan, banyak dampak negatif ketika kontrol diri tidak menjadi acuan dalam perilaku remaja.

\section{Daftar Pustaka}

Abdullah, F. (2014). Virtues and character development in Islamic ethics and positive psychology. International Journal of Education and Social Sciences (IJESS), 1(2), 69-77.

Abidin, D. Z. (2008). Al-Qur'an for life excellence. Jakarta: Hikmah.

Al-Atiq, Y. M. I. (2004). Fikih anak muslim (terjemahan). Jakarta: Al-Mahira
Al-Ghazali, I. (2008). Ringkasan ihya'ulumuddin. Jakarta Timur: Akbar Media.

Al-Jauziyah, I. Q. (2006). Tobat: Kembali kepada Allah. Gema Insani.

Anderson, J. E. (2015). Brain development in adolescents: New researchimplications for physicians and parents in egard to medical decision making. Issues L. \& Med., 30,193.

Arnett, J. J. (1995). Adolescents' uses of media for self-socialization. Journal of youth and adolescence, 24(5), 519-533.

Badriah, F. (2005). Boyz only: Petunjuk Islami kesehatan reproduksi bagi remaja cowok. Jakarta: Gema Insani.

Baumeister, R. F. (2002). Ego depletion and self-control failure: An energy model of the self's executive function. Self and identity, 1(2), 129-136.

Beaver, K. M., Wright, J. P., \& Delisi, M. (2007). Self-control as an executive function: Reformulating Gottfredson and Hirschi's parental socialization thesis. Criminal Justice and Behavior, 34(10), 1345-1361.

Blair, C., \& Razza, R. P. (2007). Relating effortful control, executive function, and false belief understanding to emerging math and literacy ability in kindergarten. Child development, 78(2), 647-663.

Brier, N. M. (2014). Enhancing self-control in adolescents: Treatment Strategies. Diunduh dari Psychological Science. New York: Routledge.

Casey, B. J., \& Caudle, K. (2013). The teenage brain self control. Psychological Science, 22(2), 82-87.

Casey, B. J., Jones, R. M., \& Hare, T. A. (2008). The adolescent brain. Annals of the New York Academy of Sciences, 1124(1), 111-126. 
Casey, B. J., Somerville, L. H., Gotlib, I. H., Ayduk, O., Franklin, N. T., Askren, M. K., \& Glover, G. (2011). Behavioral and neural correlates of delay of gratification 40 years later. Proceedings of the National Academy of Sciences, 108(36), 14998-15003.

Colver, A., \& Longwell, S. (2013). New understanding of adolescent brain development: relevance to transitional healthcare for young people with long term conditions. Archives of Disease in Childhood, 98(11), 902-907.

Crone, E. A. (2016). The adolescent brain: Changes in learning, decision-making and social relations. New York: Psychology Press.

Davis, A. S., \& D'Amato, R. C. (Eds.). (2010). Handbook of pediatric neuropsychology. New York: Springer Publishing Company.

Finkenauer, C., Engels, R., \& Baumeister, R. (2005). Parenting behaviour and adolescent behavioural and emotional problems: The role of self-control. International Journal of Behavioral Development, 29(1), 58-69.

Fox, N. A., \& Calkins, S. D. (2003). The development of self-control of emotion: intrinsic and extrinsic influences. Motivation and emotion, 27(1), 7-26.

Hamzah, K. (1991). Islam berbicara soal anak. Depok: Gema Insani.

Kompas (2017). Lima orang tewas usai pesta miras oplosan di karawang. Diunduh dari

http://regional.kompas.com/read/20 17/10/02/05305011/lima-orangtewas-usai-pesta-miras-oplosan-dikarawang pada Mei 2017.

Lerner, R. M. (2008). The good teen: Rescuing adolescence from the myths of the storm and stress years. New York: Three Rivers Press.
Lestary, H., \& Sugiharti, S. (2011). Perilaku berisiko remaja di Indonesia menurut survey kesehatan reproduksi remaja indonesia (SKRRI) Tahun 2007. Jurnal Kesehatan Reproduksi, 1(3), 136-144.

Lipsitt, L. P., \& Mitnick, L. L. (1991). Selfregulatory behavior and risk taking: Causes and consequences. New Jersey: Greenwood Publishing Group.

Manalu, J. E. R. (2017). Pedofil grup "official candy's" terkait sindikat internasional. Diunduh pada Maret 2017, dari http://www.solopos.com/2017/03/1 5/pedofil-grup-official-candys-terkaitsindikat-internasional-801724

McCullough, M. E., \& Carter, E. C. (2013). Religion, self-control, and selfregulation: How and why are they related. APA Handbook of psychology, Religion, and Spirituality, 1, 123-138.

Mischel, W., Shoda, Y., \& Rodriguez, M. L. (1989). Delay of gratification in children. Science, 244(4907), 933-938.

Putro, Y. H. (2016). Kronologi kasus kematian yuyun di tangan 14 abg bengkulu. Diunduh pada Juni 2016, dari

http://regional.liputan6.com/read/24 99720/kronologi-kasus-kematianyuyun-di-tangan-14-abg-bengkulu

Qardhawi, Y. (1998). Kebangkitan islam dalam perbincangan para pakar. Jakarta: Gema Insani.

Rathus, S. A. (2013). Childhood and adolescence: Voyages in development. USA: Cengage Learning.

Rolison, M. R., \& Scherman, A. (2002) Factors influencing adolescents' decisions to engage in risk-taking behavior. Adolescence, 37(147), 585.

Santrock, J. W. (2010). Life-span development (13 ${ }^{\text {rd }}$ Edition). New York: Mcgraw-Hill. 
Shaffer, D. D. R., \& Kipp, K. (2002). Developmental psychology: Childhood \& adolescence. Cengage Learning.

Shihab, M. Q. (2007). Secercah cahaya ilahi: Hidup bersama al-quran. Jakarta: Mizan Pustaka.

Smetana, J. G. (2010). Adolescents, families, and social development: How teens construct their worlds. John Wiley \& Sons.

Steinberg, L. (2007). Risk taking in adolescence: New perspectives from brain and behavioral science. Current Directions in Psychological Science, 16(2), 55-59

Steinberg, L., Bornstein, M. H., \& Vandell, D. L. (2010). Life-span development: Infancy through adulthood. USA: Cengage Learning.

Sulaiman, A., Jamsari, E. A., \& Noh, N. C. (2015). Islamic Environment in Child Development According to the Views of Imam Al-Ghazali. Mediterranean Journal of Social Sciences, 5(29), 33.

Weiten, W. (2012). Psychology: Themes and variations. USA: Cengage Learning.

Wills, T. A., \& Dishion, T. J. (2004). Temperament and adolescent substance use: A transactional analysis of emerging self-control. Journal of Clinical Child and Adolescent Psychology, 33(1), 69-81.

Yang, X., Zhao, J., Chen, Y., Zu, S., \& Zhao, J. (2018). Comprehensive self-control training benefits depressed college students: A six-month randomized controlled intervention trial. Journal of Affective Disorders, 226, 251-260.

Zarkasyi, H.F., \& Cholik A. (2016). Relasi Qalb dan 'Aql Menurut Imam AlGhazali. Jurnal Pemikiran dan Peradaban Islam Islamia, 11. 